\title{
Extubation following dacryocystorhinostomy: an alternative technique
}

Eye (2017) 31, 982-984; doi:10.1038/eye.2017.26; published online 17 March 2017

Nasolacrimal duct obstruction and its primary manifestations of epiphora and dacryocystitis are frequently encountered by the ophthalmologist and oculoplastic surgeon. Dacryocystorhinostomy (DCR) has been established as the prevailing procedure for acquired primary nasolacrimal duct obstruction and involves establishing direct drainage of tears from the lacrimal sac into the nasal cavity, bypassing the blocked nasolacrimal duct. Two major approaches are utilized: external, via a transcutaneous incision, and endonasal endoscopically guided. ${ }^{1}$

DCRs, whether external or endonasal, usually involve the insertion of a silicon tube, which is then tied in the nasal cavity. The predominant method of extubation is via the nasal route, ${ }^{2,3}$ which involves the division of the tube at the puncta and then expression of the tube from the nose with or without the use of an endoscope.

We describe an alternative method of extubation through the upper punctum following external DCRs.

We retrospectively reviewed the records of 61 patients who underwent external DCR between August 2007 and May 2015. Eight cases were excluded due to incomplete records. In the remaining 52 cases (one patient had bilateral surgery), the patients' age ranged from 25 to 93 years (mean $=63.71$ years). There were 17 males and 35 females. Twenty-eight DCRs were carried out on the right side and 25 were performed on the left.

The external DCR operations were performed in the conventional way by two experienced oculoplastic surgeons (VC, EGK). The steps included fashioning a large bony ostium; anterior and posterior flap formation from both the lacrimal sac and nasal mucosa and suturing of the flaps with 6/0 vicryl; bicanalicular silicone Bernard tube (Aspen Medical Ltd, Redditch, GB,
UK) passage through the upper and lower canalicular systems; tying of the tubes with two 6-0 silk sutures and release into the nose without any other method of tube fixation. The first silk suture is tied high up in the area of anastomoses of the lacrimal sac flaps and nasal mucosal flaps (Figures 1a and 2a); while the second one is tied distally, close to the nostril (Figures 1a and 2b). All patients received postoperative topical antibiotic ointment.

The tubes were removed at 3 months using the following technique:

Topical anaesthetic drops are instilled in the eye. The tube is gently engaged close to the upper punctum using a Moorfields foceps (Figure 2c). The tube is then cut with a scissors close to the lower punctum (Figures $1 b$ and $2 d$ ). The upper cut end of the tube is then pulled laterally through the upper canaliculus, to deliver the rest of the tube and sutures (Figures 1c and 2e).

To our knowledge, this method of extubation has never been described before. We believe that this technique has three main advantages over the endonasal method. First, it is an easier technique to master and can be carried out by medical and nursing staff equally. Second, it eliminates the need for special equipment such as the nasal endoscope and finally, it avoids nasal manipulation.

The disadvantages include the risk of canalicular or punctal damage and the risk of breakage of the tube with retention of part of the tube. We have not encountered the first in our cohort. Attas-Fox et al describe a method of retrieving retained stenting material by inserting the two ends of a Crawford tube through the upper punctum in the paediatric population. ${ }^{4}$ This shows that the canaliculus and punctum may be more resistant to trauma than one may think.

In our cohort, we encountered four cases $(7.5 \%)$ of retained tube material; one $(1.9 \%)$ of which required systemic antibiotics as the operation site got infected. In relation to 


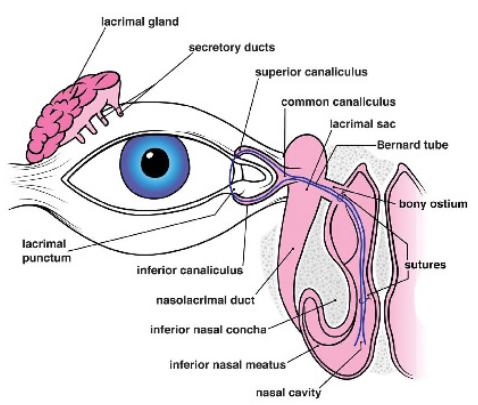

b

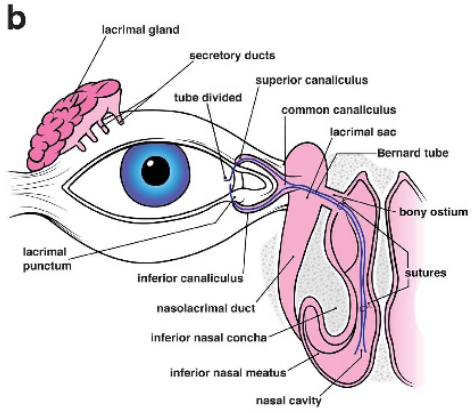

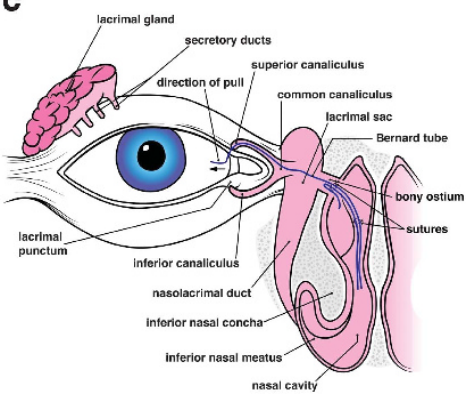

Figure 1 (a) Shows the bony ostium connecting the nasolacrimal sac to the nasal cavity, with the bicanalicular silicone Bernard tube in situ. The position of the silk sutures tying the tubes together is also depicted. (b) Illustration depicting the technique of extubation- the tube is cut close to the lower punctum. (c) Pulling the upper cut end of the tube laterally through the upper canaliculus, results in the delivery of the tube and sutures.
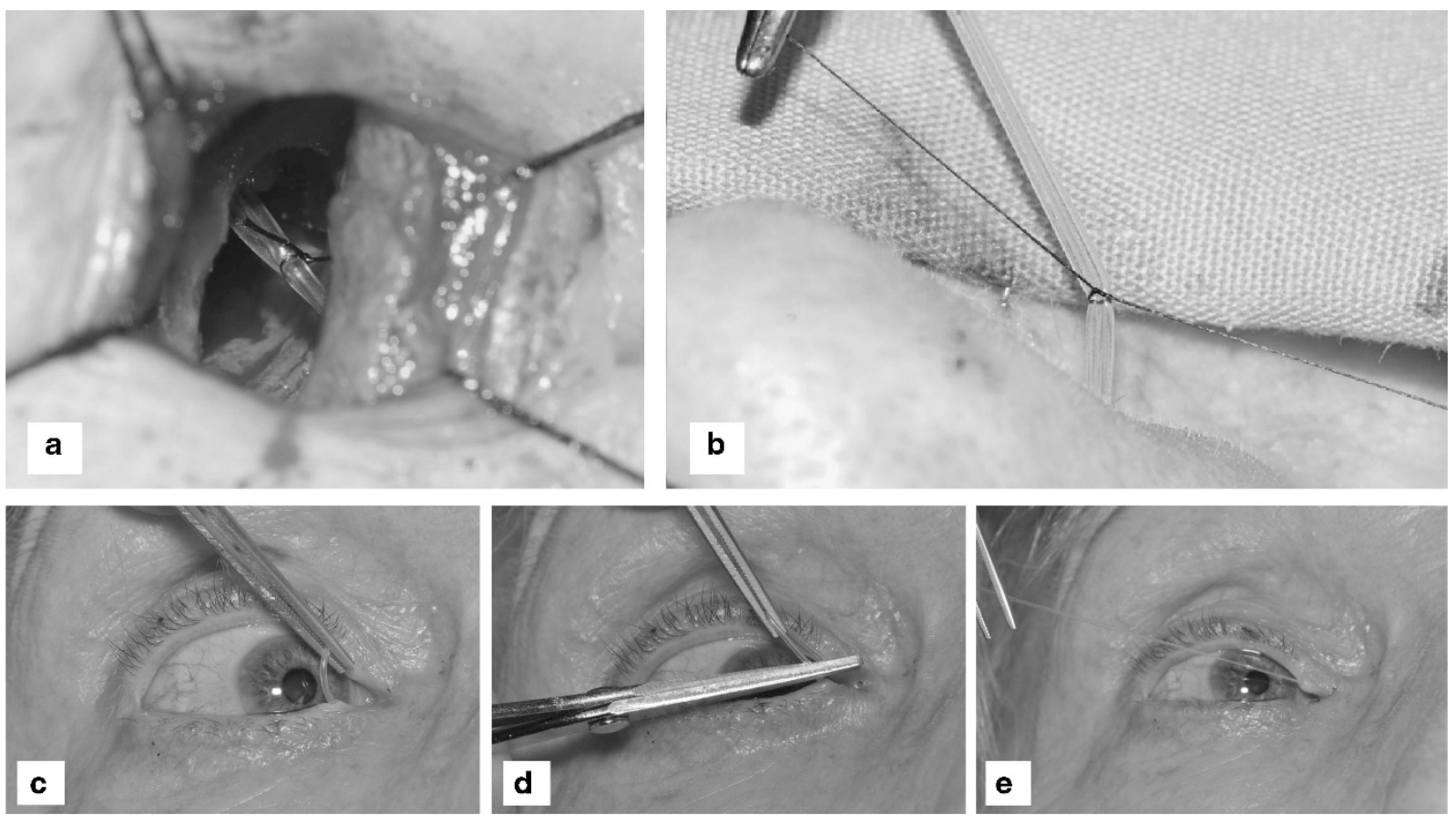

Figure 2 Peri-operative photos showing the tying of the tubes at 2 ends. The first suture is tied high up in the area of anastomoses (a); while the second one is tied distally, close to the nostril (b). Peri-operative photos showing the extubation technique. The tube is engaged (c), and divided at the lower punctum (d). The upper end of the tube is then pulled laterally to deliver the rest of the tube and sutures (e).

endonasal tube removal, there are reports of retained stenting material in literature. ${ }^{4,5}$

Anecdotally, we are aware that while using the canalicular method of extubation, some patients experience a momentary episode of discomfort. This is very short-lived and in our experience is of no real clinical significance.

In conclusion, this novel technique has proved to be an easy, safe, and effective alternative way of extubation following external DCRs.

\section{Conflict of interest}

The authors declare no conflict of interest.

\section{References}

1 Harish V, Benger RS. Origins of lacrimal surgery, and evolution of dacryocystorhinostomy to the present. Clin Exp Ophthalmol 2014; 42(3): 284-287.

2 Ali MJ, Manderwad G, Naik MN. The microbiological spectrum and antibiotic sensitivity profile of extubated 
silicone stents following dacryocystorhinostomy. Orbit 2013; 32(5): 298-303.

3 Ali MJ, Gupta H, Naik MN, Honavar SG. Endoscopic guided single self-linking silicone stent in pediatric external dacryocystorhinostomy. Minim Invasive Ther Allied Technol 2013; 22(5): 266-270.

4 Attas-Fox L, Codère F. Nonsurgical retrieval of retained lacrimal stenting material. Ophthal Plast Reconstr Surg 2012; 28(4): 303-304.

5 Then SY, O'Donnell A, Beigi B, Malhotra R. Retained silicone sleeve as a cause of dacryocystorhinostomy failure. Ophthal Plast Reconstr Surg 2007; 23(6): 492-493.
M Galea, F Shams, E Saxby, E Newcott, V Chadha and E Kemp

Tennets Institute of Ophthalmology, Gartnavel General Hospital, Glasgow, UK

Correspondence: F Shams, NHS Greater Glasgow and Clyde, Tennent Institute of Ophthalmology, Gartnavel General Hospital, 1053 Great Western Road, Glasgow G12 0YN, UK Tel: 01412113000 . E-mail: fshams@doctors.org.uk 